\title{
Defining “Feeling Leadership” For New Leadership Practice in Modern Management
}

\author{
Md. Sadique Shaikh* and Safina Khan \\ KYDSC Trust's Institute of Management \& science, India
}

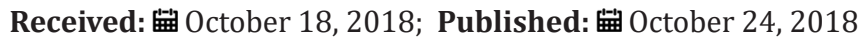

*Corresponding author: Md. Sadique Shaikh, KYDSC Trust's Institute of Management \& science, Sakegaon-Bhusawal, M.S, India

\begin{abstract}
I was started my research only with one thinking "How we feel and understand sadness or happiness of others, why our eyes sometime filled with tears, when we see others crying or sad, why we cheer up when we see others happy, why we bless others, why we care for others, why we become sad when we watch sad seen in movies, why we motivate when we watch something exciting and meaningful in movies, why, why and why?" these are the big questions front of us. My common answer which support to all these questions is "when situation is common between two or more than two people they completely understand each other, because their brains neurons handling same situation. Some time may be feelings for other because of past common situation of us is the present situation of someone or may be some time we think if that situation on me what I would do. Hence common situation either good or bad doesn't matter but common situation people show strong feelings about each other with respecting emotions and feelings of each other's and this is because "common situation setup brain-to-brain link between people through which they understand feelings and emotions of each other [1].
\end{abstract}

Keywords: Mirror Neurons; Neuroscience; Feeling Leadership; Biological Leadership; Personable Leadership

\section{Mirror Neurons Density Model for Feelings}

\section{Leadership Pattern of Leaders Brain}

Above model is developed with the intention to understand the role of Mirror Neurons in Feelings Leadership with the help of MNs density in Business leader's brain which make their leadership patterns more and more personable. After several social psychological reviews and practice I came to conclude this model. If density of MN found low in the people who are leaders, they observed generally emotionless and feelings less and unable to understand others or some time due to high level of ego don't want to understand others. Hence leadership patterns in such human beings "Autocratic" and most dictate leaders. Where as if MNs density average situation slightly different, people who has average density found they have feelings and emotion for others but not so strong and the leadership pattern of such a leaders democratic but not personable/feelings leadership. This happen only when MNs density very high in people who are leaders, due to high density of MNs leader link his/her brain with the brains of their subordinates/team members and with tracing/scanning their brains completely understand emotions and feelings of others and lead according to it without hurting business organization [2].

\section{Traits Model of Feelings Leadership}

My second model I developed to understand, what are the important criteria to maintain and keep update full flagged feelings leadership in people who are business leaders during execution of business. Hence these are the some necessary factors need to be maintain for feelings leadership pattern as well as to increase MNs density in brain to make leadership very close and personable to teams/organizations (Figures 1-4). Like Transparency to know emotions of others, Brain-to-Brain link formation to know others, Brain reading ability of others with Empathy and learning, Behavior and body language patterns acquiring ability of others etc. and off course for these factors strong cognitive ability with MNs $=100 \%$ density of mirror neurons need in leaders.

\section{Integrated Model for Feelings Leadership}

This model highlighted the parameters must need to integrate for strong Personable/Feelings Leadership development and implementation in business organizations. Feelings leadership strongly based on human biology, especially human psychology.i.e. study and use of "brain in business". Studies conducted by Harvard 
Business School and Kellogg's School of Management purposed several theories and researches about investigation and effect of Mirror Neurons in behavior of individual and stated that it's also useful study in business leadership, but proper name was not given to it [3-9]. I found name either Biological leadership, social leadership or personable leadership, where personable leadership is best name to MNs oriented leadership pattern, but still very freshly and first time I named this leadership pattern "Feelings Leadership". This leadership also has strong involvement of all human biological sensory and actuation.i.e. strong cognitive Science. To make it most perfect finally it's needs support of theories and postulates of human/social psychology and business leadership pattern and styles.

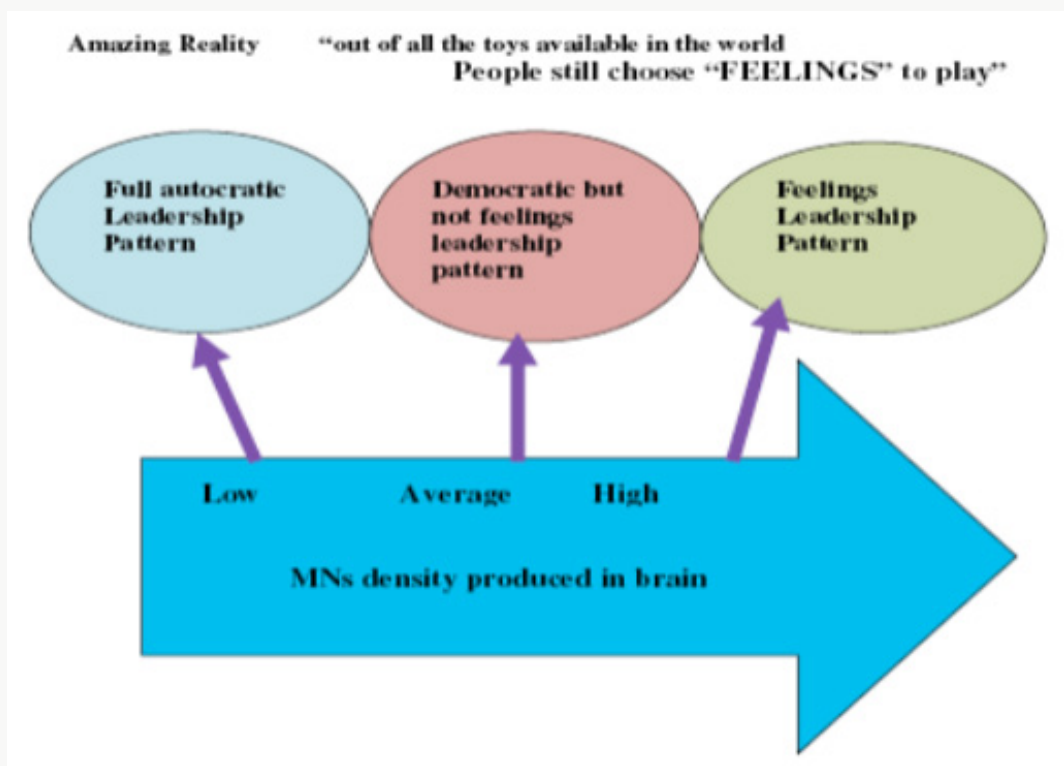

Exhibit-One: Source-Prof. Md. Sadique Shaikh

Figure 1

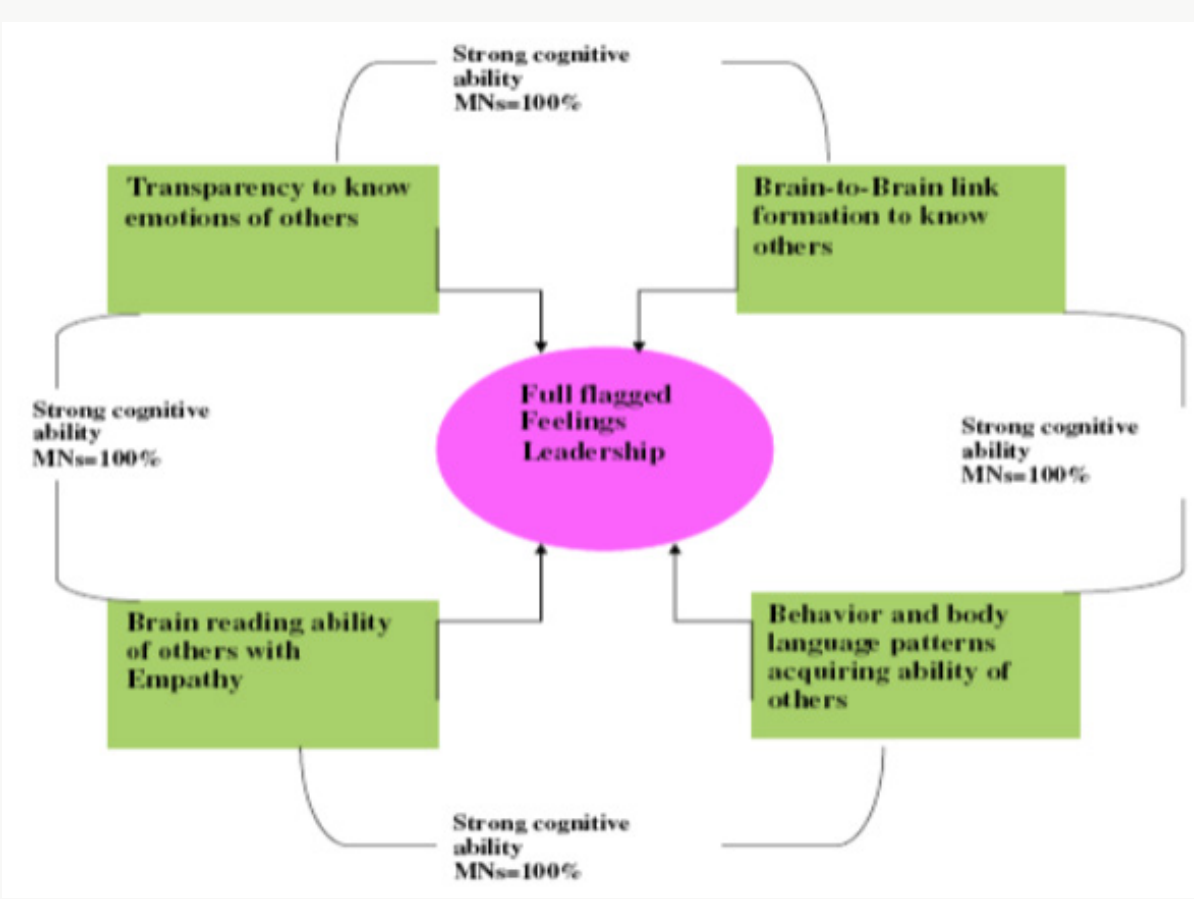

Figure 2 


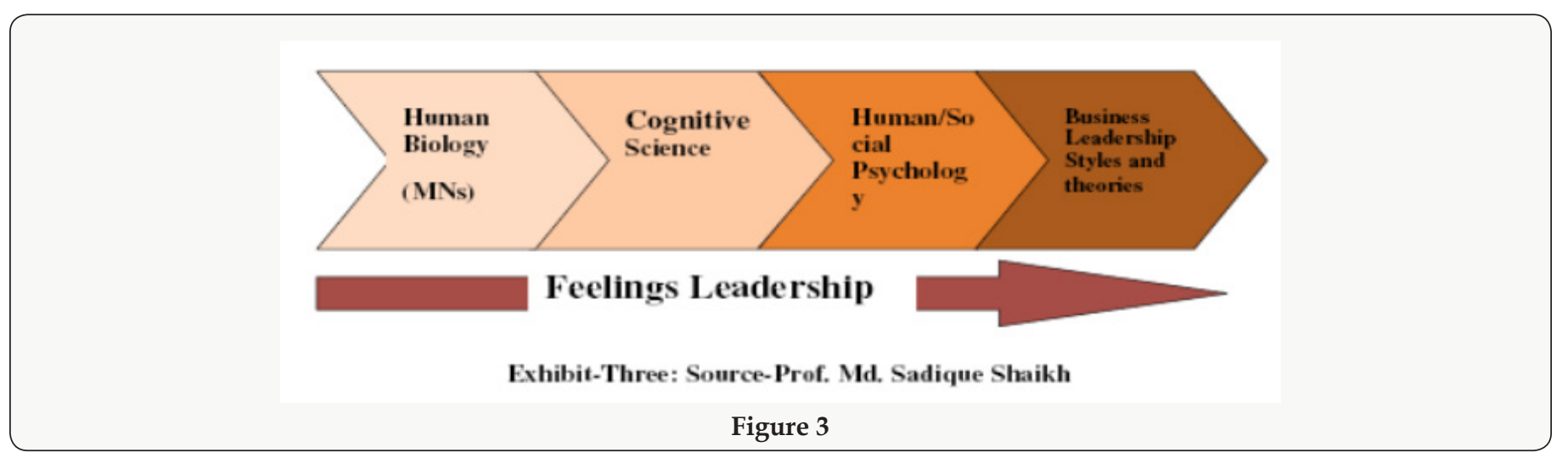

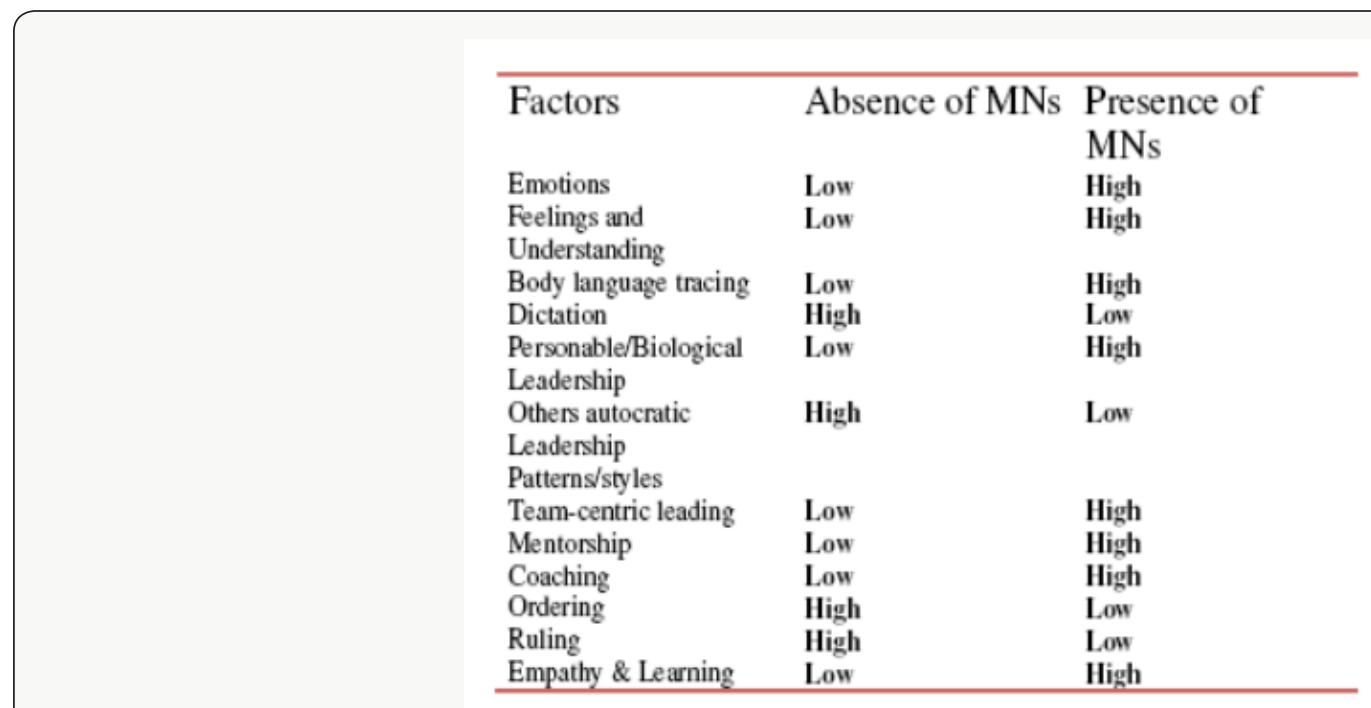

Exhibit-Four: Source-Prof. Md. Sadique Shaikh

Figure 4

Factors Model With/Without Mirror Neurons (MNs)

This is self-explanatory tabular models, which demonstrate several important factors for feelings leadership style which only achieve with high MNs density. The above exhibit focused effect of presence and absence of NMs on all these factors, which modeled in previous three models in detail [10-11].

\section{Conclusion}

In my communication I coined and discussed very fresh and new term to enhance research in business leadership in new direction with leading effectively to Organizations. I discussed four models which are based and extracted from Neuroscience to define term "Mirror Neurons" which is the backbone of "Feeling Leadership". Though some theories defined term biological or personable leadership, but phenomenon of feeling leadership is completely different and vital for new business horizon I discussed with models.

\section{Acknowledgement}

I really thankful to my wife Safeena Shaikh for her moral support my son Md. Nameer Shaikh \& Md. Shadaan Shaikh for their love which keeps me fresh with new ideas and my close friend \& Co-author Tanvir Sayyed for her positive support with me and my motivator Dr. B.N.Gupta for his constant support.

\section{References}

1. Argyris C (1966) interpersonal Barriers to Decision-Making. Harvard Business Review pp. 84-97.

2. Argyris C (1971) Management information systems: The Challenge to Rationality and emotionality. Management Science 17(6): 275-292.

3. Arnsten AFT (1998) The Biology of Being Frazzled. Science 280(5370): 1711- 1712.

4. Beauregard M (2007) Mind does really matter: evidence from neuroimaging studies of emotional self-regulation, psychotherapy, and placebo effect. Progress in Neurobiology 81(4): 218-236.

5. Brousseau K, Driver M, Hourihan G, Larsson R (2006) The seasoned executive's Decision-Making style. Harvard Business Review 84(2): 111112

6. Gallese V, Keysers C, Rizzolatti G (2004) A unifying view of the basis of social cognition. Trends Cognitive science 8(9): 396-403.

7. Goleman D, Boyatzis Re, McKee A (2002) Primal Leadership: Realizing the Power of emotional intelligence. Boston: Harvard Business school Press.

8. Kotter JP, Schlesinger LA (1979) Choosing strategies for Change. Harvard Business Review 57(2): 106-114. 
9. Montgomery KJ, Haxby JV (2008) Mirror neuron system differentially activated by facial expressions and social hand gestures: A functional magnetic resonance imaging study. Journal of Cognitive Neuroscience 20(10): 1866-1877.

10. Md. Sadique Shaikh (2013) Feelings leadership: Redefining Business Leadership Concept with significance of MIRROR NEURONS from neuroscience and Biological Context in Excel International Journal of Multidisciplinary Management Studies 3(11): 110-125.

11. Md Sadique Shaikh, Feelings Leadership, LAP-Lambert Academic Publication, Germany.

\section{(c) (i) \\ This work is licensed under Creative Commons Attribution 4.0 License}

To Submit Your Article Click Here:

Submit Article

DOI: $10.32474 /$ ARME.2018.01.000114

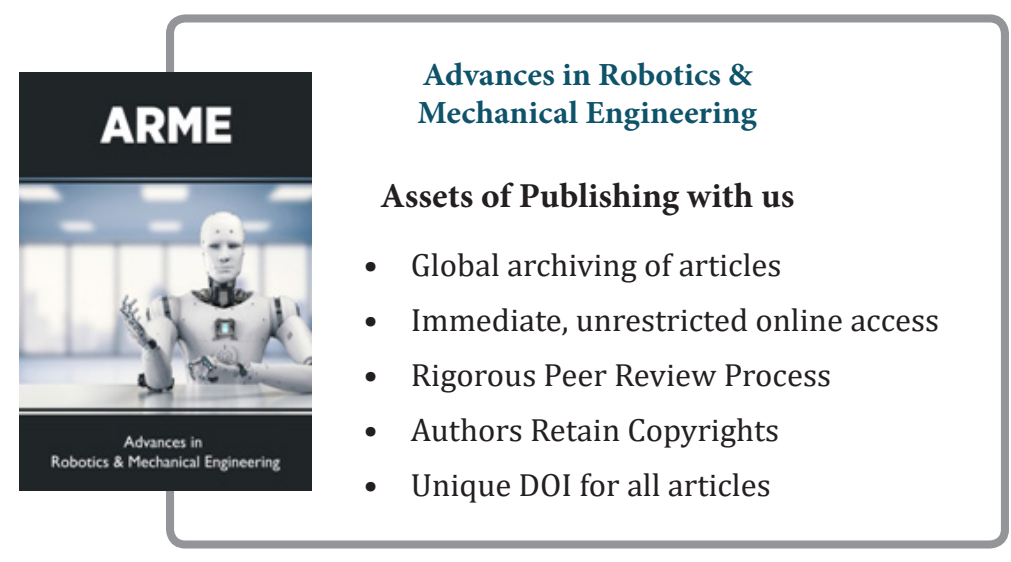

